\title{
Pseudomonas otitidis sp. nov., isolated from patients with otic infections
}

\author{
Linda L. Clark, Joseph J. Dajcs, Celeste H. McLean, John G. Bartell \\ and David W. Stroman
}

Correspondence

Alcon Research Ltd, 6201 South Freeway, R0-17, Fort Worth, TX 76134-2099, USA

David W. Stroman

David.Stroman@alconlabs.com

\begin{abstract}
A novel Pseudomonas species, for which the name Pseudomonas otitidis sp. nov. is proposed, was identified from clinical specimens of infected human ears. Forty-one pseudomonads (34 from patients with acute otitis externa, six from patients with acute otitis media with otorhoea and one from a patient with chronic suppurative otitis media) were recovered that did not match any known species. On the basis of genetic analyses and biochemical characterization, these isolates were shown to belong to the genus Pseudomonas. 16S rRNA gene sequence analysis and DNADNA hybridization studies indicated that this novel bacterium is closely related to, but different from, Pseudomonas aeruginosa. A description of this species is based on polyphasic studies of 11 clinical isolates. The type strain of Pseudomonas otitidis is MCC $10330^{\top}$ (=ATCC BAA$1130^{\top}=$ DSM $17224^{\top}$ ).
\end{abstract}

The genus Pseudomonas was first described by Migula (1894) and since then members of the genus have been isolated from humans, plants and various environmental habitats, such as soil (Roland \& Stroman, 2002; Munsch et al., 2002; Ivanova et al., 2002; Sikorski et al., 2001). The genus Pseudomonas was formerly described by Palleroni (1984) as consisting of more than 100 species of phylogenetically unrelated groups of Proteobacteria. Palleroni et al. (1973), using genetic analysis, specifically rRNA-DNA hybridization, subdivided the genus into five rRNA groups (I-V). Kersters et al. (1996) have summarized the changes in the reclassification of the former Pseudomonas species, which are now classified into several genera belonging to the Alphaproteobacteria, Betaproteobacteria or Gammaproteobacteria. Species belonging to the genus Pseudomonas sensu stricto are now placed in rRNA group I (Palleroni, 1984), which belongs to the Gammaproteobacteria (Kersters et al., 1996; Achouak et al., 2000). In the past two decades, polyphasic taxonomic studies, especially those using genetic and molecular techniques, have played a critical role in improving the classification of the pseudomonads (Anzai et al., 2000). Many of the organisms originally described as species of the genus Pseudomonas have been reclassified to other genera.

Abbreviation: MIC, minimal inhibitory concentration.

The GenBank/EMBL/DDBJ accession number for the 16S rRNA gene sequence of $M C C 10330^{\top}$ is $A Y 953147$.

Tables detailing the biochemical and phenotypic characteristics of individual novel strains and the cellular fatty acid composition of the novel strains and related Pseudomonas species are available as supplementary material in IJSEM Online.
Novel pseudomonads were recovered from the ears of patients enrolled in anti-infective clinical studies. In total, 41 novel pseudomonads were recovered from ears of patients diagnosed with acute otitis externa $(n=34)$, otitis media with otorrhoea drainage through a tympanostomy tube $(n=6)$ and chronic suppurative otitis media $(n=1)$. A brief description of the source of 11 representative isolates is listed in Table 1. At clinical examination, a swab was used to sample each patient's ears, and the swabs were then immediately placed into transport media. Swabs were removed from transport media and cultured onto various media to obtain viable colonies and then subcultured to obtain a pure culture. Isolated colonies were transferred to trypticase soy broth supplemented with $10 \%$ glycerol and stored in liquid nitrogen. Bacteria were thawed and cultured onto blood agar prior to genetic or phenotypic analyses. DNA-DNA hybridization, comparative 16S rRNA gene sequencing and phenotypic analysis identified these organisms as members of a novel Pseudomonas species. The novel pseudomonads were compared with the type strains of Pseudomonas alcaligenes, $P$. aeruginosa, $P$. citronellolis, $P$. multiresinovorans, $P$. nitroreducens, $P$. resinovorans and $P$. stutzeri, which were acquired from the ATCC.

Ribotyping was performed on all 41 strains with the RiboPrinter Microbial Characterization System (DuPont Qualicon) following the manufacturer's recommendations. The novel strains underwent ribotype analyses using a standard riboprinting kit incorporating EcoRI restriction endonuclease for species-level identification and PstI and $P v u I I$ endonuclease digestion for strain-level differentiation. EcoRI endonuclease digestion of the novel strains produced 
Table 1. Sources of Pseudomonas otitidis sp. nov. isolates

F, Female; M, male.

\begin{tabular}{|lcrl|}
\hline Strain & Gender & $\begin{array}{c}\text { Age } \\
\text { (years) }\end{array}$ & \\
\hline MCC09159 & F & 40 & Chronic suppurative otitis media \\
MCC10330 & M & 6 & Acute otitis externa \\
MCC10429 & M & 13 & Acute otitis externa \\
MCC10744 & F & 11 & Acute otitis externa \\
MCC11140 & M & 24 & Acute otitis externa \\
MCC11338 & M & 60 & Acute otitis externa \\
MCC11683 & F & 16 & Acute otitis externa \\
MCC12065 & M & 33 & Acute otitis externa \\
MCC12178 & F & 15 & Acute otitis externa \\
MCC40150 & M & 9 & Otitis media with otorroea drainage through tympanostomy tube \\
MCC51196 & M & 3 & Otitis media with otorrhoea drainage through tympanostomy tube \\
& & & \\
\hline
\end{tabular}

a predominant ribotype pattern (39 of 41 strains) with a distinct band at $5.3 \mathrm{kbp}$; this particular band was shifted to $6 \mathrm{kbp}$ for the two remaining isolates. A representative pattern for the novel taxon is compared with the patterns of the type strains of $P$. aeruginosa, $P$. resinovorans, $P$. alcaligenes, $P$. citronellolis and P. stutzeri in Fig. 1. Strainlevel discrimination of the new isolates is shown in Fig. 2. The ribotype pattern of the PstI digests revealed a band at $6.9 \mathrm{kbp}$ that was present for every isolate, and the majority of isolates had double bands at approximately $6 \cdot 5-7 \cdot 5 \mathrm{kbp}$. Other bands were present, but no discernible pattern was noted. The ribotype pattern of PvuII digests showed a distinct band at $3 \cdot 4 \mathrm{kbp}$ that was present for all the isolates. Ribotype patterns of PvuII digestion also produced numerous bands that did not demonstrate any obvious patterns or similarity between isolates.

Bacterial genomic DNA for comparative sequence analysis was extracted using PrepMan UltraSample preparation reagent (Applied Biosystems). Approximately $1451 \mathrm{nt}$ of the $16 \mathrm{~S}$ rRNA gene was amplified by PCR using the MicroSeq

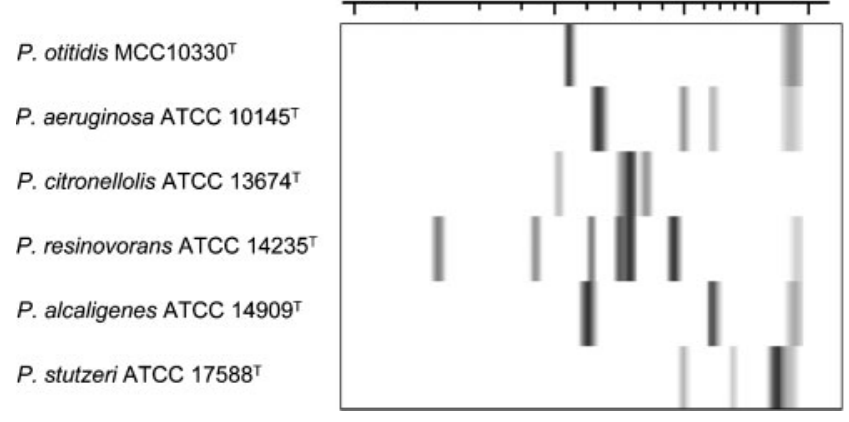

Fig. 1. Riboprint patterns using $E_{c o R}$ restriction endonuclease comparing representative novel isolate $\mathrm{MCC}_{10330^{\top}}$ with related type strains.
Full Gene kit (Applied Biosystems). PCR products were sequenced with the MicroSeq Full Gene 16S rRNA gene bacterial sequencing kit (Applied Biosystems). Sequences were determined with a 3100-Avant Genetic Analyzer (Applied Biosystems). Phylogenetic analysis was performed using MicroSeq Microbial Identification software version 1.4.1 and BioNumerics software version 3.5 (Applied Maths). Full 16S rRNA gene sequences of Pseudomonas species were obtained from GenBank (http://www.ncbi.nlm.nih.gov/entrez/). A phylogenetic tree comparing species of Pseudomonas sensu stricto that were closely related to the novel taxon was created in BioNumerics by using the neighbour-joining method with a pairwise alignment and no correction factors. Comparative sequence analysis of the 16S rRNA gene revealed that representative strain $\mathrm{MCC} 10330^{\mathrm{T}}$ is a member of the Gammaproteobacteria and that this organism should be included in the genus Pseudomonas. Fig. 3, a phylogenetic tree obtained by using the neighbour-joining method, shows the phylogenetic placement of MCC $10330^{\mathrm{T}}$ branching with $P$. aeruginosa $(98.6 \% 16 \mathrm{~S}$ rRNA gene sequence similarity). The other species most closely related (percentage sequence similarity) to MCC $10330^{\mathrm{T}}$ were $P$. alcaligenes $(98 \cdot 2 \%), \quad P$. stutzeri (98.0\%), P. resinovorans (97.5\%), Pseudomonas pseudoalcaligenes $(97 \cdot 1 \%)$ and $P$. citronellolis $(96 \cdot 9 \%)$.

Genomic DNA for spectroscopic DNA-DNA hybridization studies was isolated using a French pressure cell (Thermo Spectronic) and purified by chromatography on hydroxyapatite, as described by Cashion et al. (1977). DNA-DNA hybridization was carried out as described by De Ley et al. (1970) with the modifications suggested by Huß et al. (1983) using a Cary 100 Bio UV/Vis spectrophotometer equipped with a Peltier-thermostatted $6 \times 6$ multicell changer and a temperature controller with in-situ temperature probe (Varian). DNA-DNA hybridizations (performed in duplicate) between the new taxon and other related pseudomonads had the following binding values (percentage relatedness): P. alcaligenes (55\%), P. citronellolis (44\%), 


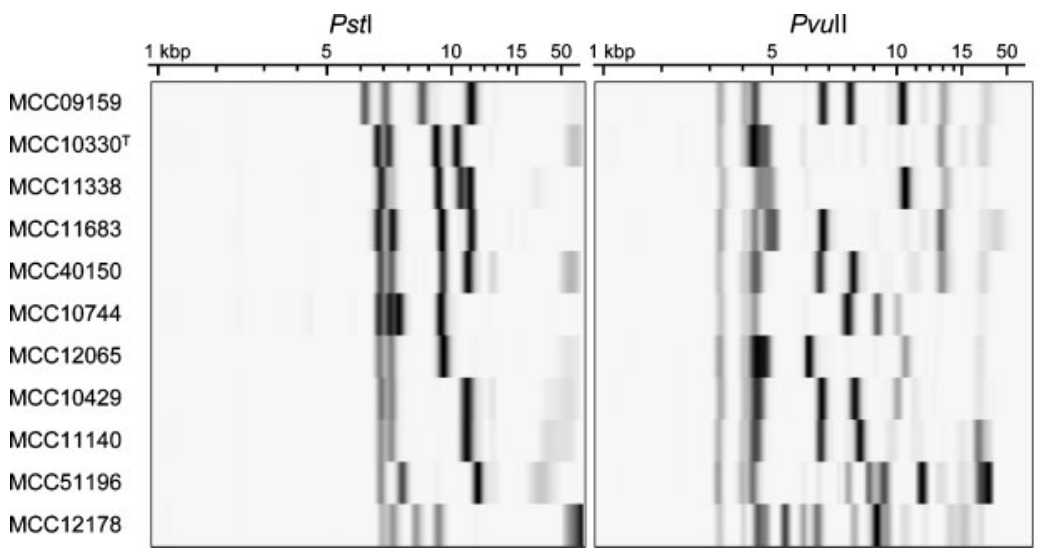

Fig. 2. Strain-level discrimination of 11 representative isolates of Pseudomonas otitidis sp. nov. using Pstl and Pvull endonuclease digestion.

P. aeruginosa (40\%), P. nitroreducens (41\%), P. resinovorans (19\%) and P. stutzeri (12\%). Given a threshold level of $70 \%$ DNA-DNA relatedness used to delineate a bacterial species, as recommended by Wayne et al. (1987), the results indicated that MCC $10330^{\mathrm{T}}$ did not belong to any of the Pseudomonas species tested. The DNA G $+\mathrm{C}$ content of MCC $10330^{\mathrm{T}}$ was $67 \cdot 9 \mathrm{~mol} \%$.

The 11 representative novel strains were evaluated for phenotypic characteristics and compared with the type strains of $P$. aeruginosa, $P$. citronellolis and $P$. stutzeri (Table 2; results for the individual novel strains are given in Supplementary Table S1 in IJSEM Online). Carbon substrate utilization was determined using the Biolog GN MicroPlate System and VITEK32 (bioMérieux). The presence of oxidase, catalase and urease activity, production of fluorescent pigments, hydrolysis of Tween 80, aesculin, starch and casein, motility in semisolid media, tolerance of $\mathrm{NaCl}$ and minimal and maximal temperature range were all assayed according to standard procedures. Cells of the novel strains were motile, Gram-negative, non-spore-forming rods occurring as single cells. Growth occurred at temperatures of $7-45^{\circ} \mathrm{C}$, but no growth was observed at 4 or $47^{\circ} \mathrm{C}$. Growth occurred on solid media supplemented with $0-4 \% \mathrm{NaCl}(\mathrm{w} / \mathrm{v})$, but not at higher salinity. Growth was observed in media only at $\mathrm{pH} 5-10$. The majority of the novel strains (10 of 11 ) failed to produce pyocyanin or fluorescein, whereas both $P$. aeruginosa and $P$. citronellolis produced these pigments. Each strain had positive reactions for oxidase and catalase, but all were negative for urease. The novel strains were relatively homogeneous in their metabolic characteristics. They differed from the reference strains in utilization of glycerol, D-gluconic acid, itaconic acid, D-fructose, D-mannitol, acetic acid, cytosine, $\beta$-phenylethylamine and sebacic acid.

Cellular fatty acid analyses were performed with the MIDI Sherlock Microbial Identification System and a Hewlett Packard gas chromatograph to identify cellular fatty acids qualitatively and quantitatively. The fatty acid compositions of the novel strains and related Pseudomonas species are given in Supplementary Table S2 available in IJSEM Online. The major fatty acids detected (percentage of the total cellular fatty acids) from the novel strains were $\mathrm{C}_{18: 1} \omega 7 c(32.9 \%), \mathrm{C}_{16: 0}(26.9 \%), \mathrm{C}_{12: 0}(9 \cdot 1 \%), \mathrm{C}_{12: 0}$ $3-\mathrm{OH}(4 \cdot 0 \%)$ and $\mathrm{C}_{10: 0} 3-\mathrm{OH}(2 \cdot 8 \%) . \mathrm{C}_{12: 0} 3-\mathrm{OH}$ is consistently found in members of the genus Pseudomonas sensu stricto (Oyauzu \& Komagata, 1983). The fatty acid compositions of the reference pseudomonads assayed were qualitatively similar to but varied in concentration from those of the novel strains.

Minimal inhibitory concentrations (MIC) were determined using the National Committee for Clinical Laboratory

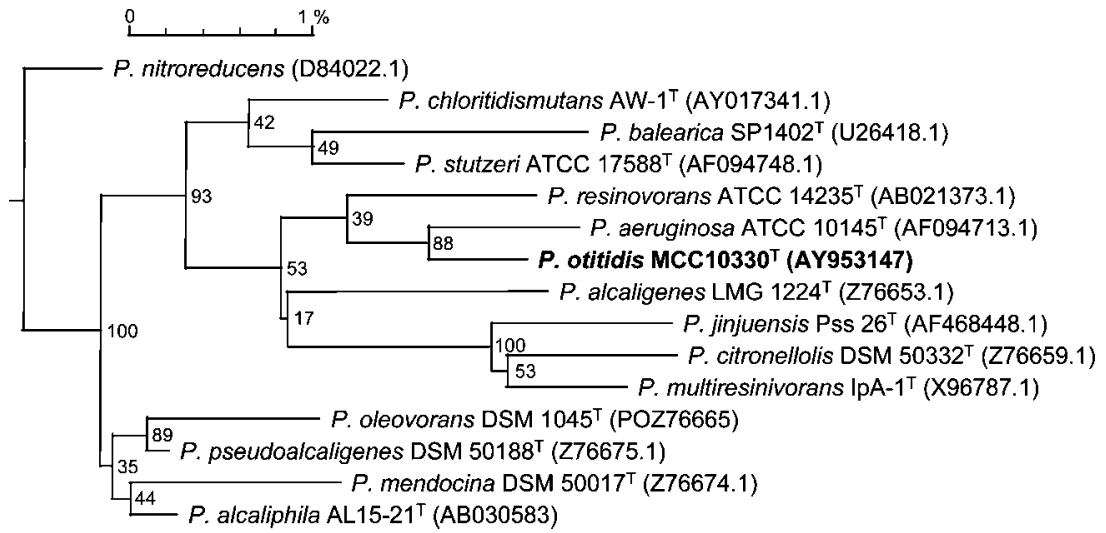

Fig. 3. Neighbour-joining tree, based on $16 \mathrm{~S}$ rRNA gene sequence analysis ( $\sim 1500 \mathrm{bp}$ ), showing the phylogenetic relationship of Pseudomonas otitidis sp. nov. and other closely related members of the genus Pseudomonas. Numbers at nodes are percentages of bootstrap support based on neighbourjoining analyses of 1500 resampled datasets. GenBank accession numbers are given in parentheses. The scale indicates percentage sequence divergence. 
Table 2. Phenotypic and biochemical characteristics of strains of Pseudomonas otitidis sp. nov. and type strains of related Pseudomonas species

For P. otitidis strains, the results for the type strain and for the 10 other tested strains are given; for strain-dependent properties, the number of strains showing the majority characteristic/number of strains tested is shown. Results for individual novel strains are available in Supplementary Table S1 in IJSEM Online. Results are scored as: +, positive; -, negative; d, variable result. All strains were positive for growth at $45^{\circ} \mathrm{C}$, catalase and oxidase, motility, hydrolysis of Tween 80 and utilization of glycogen, $\alpha$-D-glucose, acetic acid, citric acid, formic acid, lactic acid, propionic acid, succinic acid, D-alanine, L-alanine, L-asparagine, L-aspartic acid, L-glutamic acid and L-proline. All strains were negative for growth on $6 \%(\mathrm{w} / \mathrm{v}) \mathrm{NaCl}$ agar, indole and aesculin and for utilization of $N$-acetyl-D-galactosamine, adonitol, L-arabinose, i-erythritol, myo-inositol, xylitol, $\alpha$-D-lactose, D-mannose, D-melibiose, D-raffinose, L-rhamnose, turanose and thymidine.

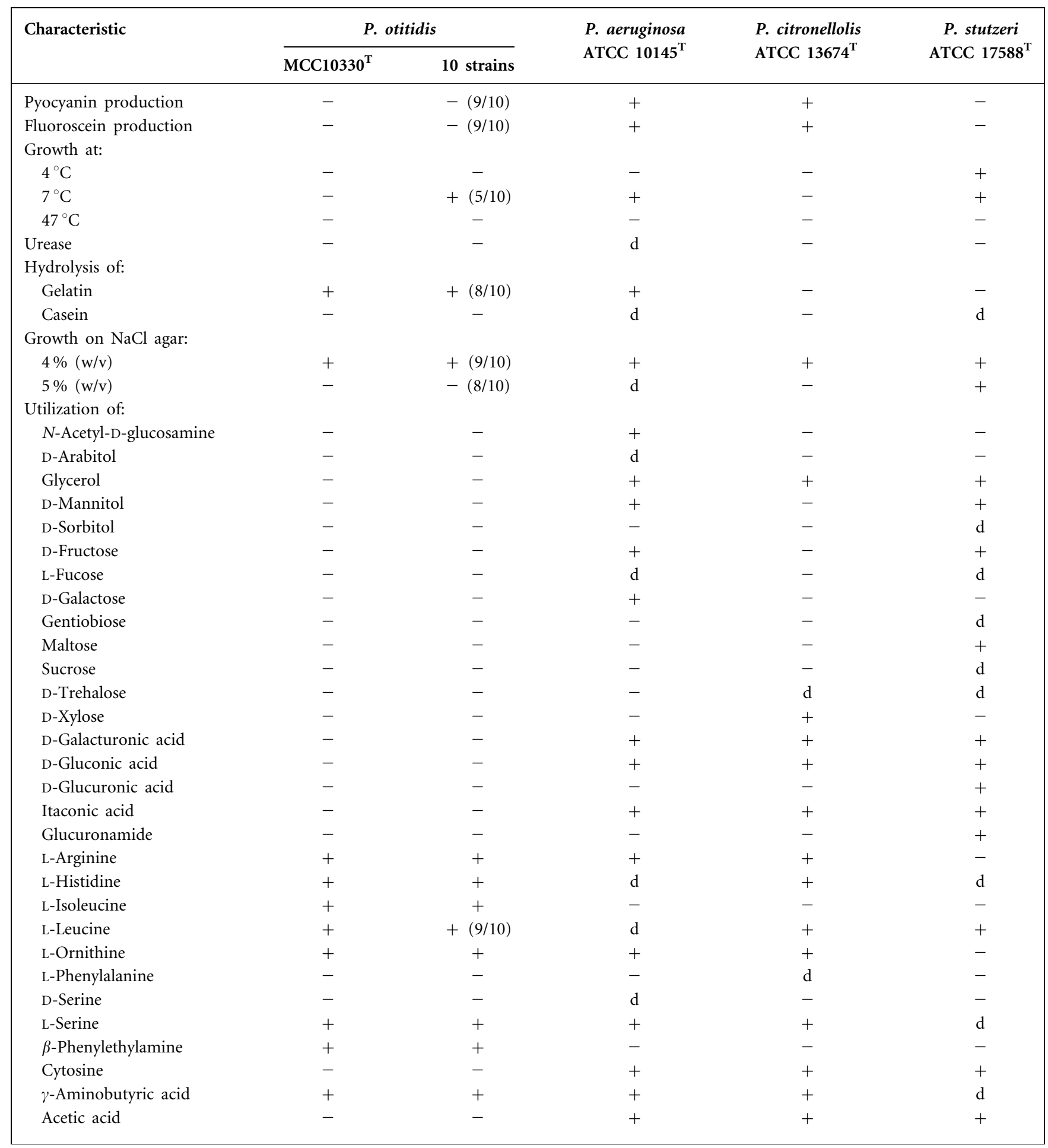


Table 2. cont.

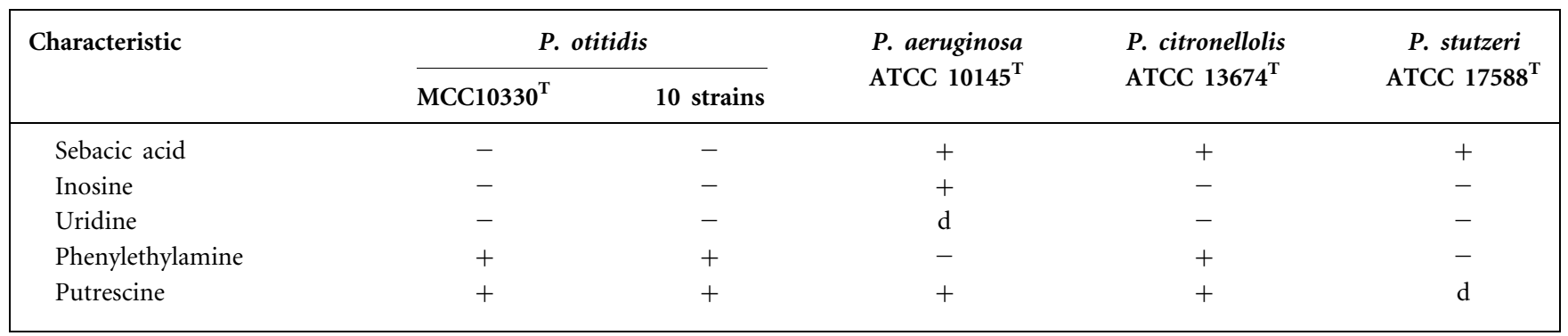

Standards broth microdilution method (NCCLS, 2003). Microdilution plates (96 wells) contained specific concentrations of antibiotic incorporated into the wells (PML Microbiologicals). Microdilution plates were inoculated with approximately $5 \times 10^{5}$ c.f.u. bacteria $\mathrm{ml}^{-1}$ and incubated overnight at $35^{\circ} \mathrm{C}$. The MIC was defined as the lowest concentration of antibiotic that inhibits growth of an organism as determined by lack of turbidity. The concentrations of antibiotic that inhibited the growth of $50 \%\left(\mathrm{MIC}_{50}\right)$ or $90 \%\left(\mathrm{MIC}_{90}\right)$ of the number of novel strains tested were determined. Antibiotic plates were analysed using a 96-well microplate reader (Dynatech Laboratories) at a wavelength of $590 \mathrm{~nm}$ and further analysed by visual inspection to determine turbidity. The novel strains exhibited similar antibiotic susceptibility profiles (Table 3 ). The isolates were susceptible to aminoglycosides (tobramycin, neomycin, gentamicin), fluoroquinolones (ciprofloxacin, ofloxacin, moxifloxacin) and polymyxin B. However, piperacillin, erythromycin, tetracycline, chloramphenicol, trimethoprim and sulfamethoxazole had minimal ability to inhibit growth of the organisms.

\section{Description of Pseudomonas otitidis sp. nov.}

Pseudomonas otitidis (o.ti'ti.dis. Gr. n. ous, otos ear; N.L. suff. -itis, -idis used in names of inflammations; N.L. gen. n. otitidis of inflammation of the ear).

Cells are Gram-negative, motile rods. Colonies on trypticase soy agar are circular, concave and non-pigmented. Colonies grown on trypticase soy agar supplemented with $5 \%$ sheep blood are not haemolytic. Growth occurs at $7-45^{\circ} \mathrm{C}$, $\mathrm{pH} 5-10$ and in the presence of up to $4 \% \mathrm{NaCl}$. Colonies typically do not produce fluorescent pigment, and all strains are positive for oxidase and catalase, but negative for urease. Tween 80 and gelatin are hydrolysed, but casein and aesculin are not. Utilizes glycogen, $\alpha$-D-glucose, acetic acid, citric acid, formic acid, lactic acid, propionic acid, succinic acid, D-alanine, L-alanine, L-arginine, L-asparagine, L-aspartic acid, L-glutamic acid, L-histidine, L-leucine, L-ornithine, L-proline, L-serine, $\gamma$-aminobutyric acid, phenylethylamine and putrescine. None of the strains utilizes $\mathrm{N}$ acetyl-D-galactosamine, $\mathrm{N}$-acetyl-D-glucosamine, adonitol, D-arabitol, L-arabinose, i-erythritol, myo-inositol, glycerol, D-mannitol, D-sorbitol, xylitol, D-fructose, L-fucose,

Table 3. MIC of various antibiotics for Pseudomonas otitidis sp. nov. $(n=41)$

The $\mathrm{MIC}_{50}$ is defined as the concentration of antibiotic that inhibits the growth of $50 \%$ of the organisms tested, whereas the $\mathrm{MIC}_{90}$ is the concentration of antibiotic that inhibits the growth of $90 \%$ of the organisms tested.

\begin{tabular}{|lccc|}
\hline Antibiotic & MIC $_{\mathbf{5 0}}\left(\boldsymbol{\mu} \mathbf{~ m l}^{-\mathbf{1}}\right)$ & $\mathbf{M I C}_{\mathbf{9 0}}\left(\boldsymbol{\mu} \mathbf{~ m l}^{-\mathbf{1}}\right)$ & $\mathbf{M I C}_{\mathbf{~ r a n g e}}\left(\boldsymbol{\mu g} \mathbf{~ m l}^{-\mathbf{1}}\right)$ \\
\hline Tobramycin & $0 \cdot 50$ & $1 \cdot 0$ & $0 \cdot 13-1 \cdot 0$ \\
Gentamicin & $0 \cdot 25$ & $1 \cdot 0$ & $0 \cdot 13-1 \cdot 0$ \\
Neomycin & $2 \cdot 0$ & $4 \cdot 0$ & $2 \cdot 0-8 \cdot 0$ \\
Piperacillin & $8 \cdot 0$ & $4 \cdot 0$ & $2 \cdot 0-16$ \\
Ciprofloxacin & $0 \cdot 06$ & $0 \cdot 13$ & $0 \cdot 03-0 \cdot 13$ \\
Ofloxacin & $0 \cdot 50$ & $1 \cdot 0$ & $0 \cdot 25-2 \cdot 0$ \\
Moxifloxacin & $1 \cdot 0$ & $2 \cdot 0$ & $0 \cdot 50-2 \cdot 0$ \\
Polymyxin B & $0 \cdot 50$ & $1 \cdot 0$ & $0 \cdot 25-2 \cdot 0$ \\
Erythromycin & 256 & 512 & $256-512$ \\
Tetracycline & $4 \cdot 0$ & $8 \cdot 0$ & $4 \cdot 0-16$ \\
Chloramphenicol & 64 & 128 & $32 \cdot 0->256$ \\
Trimethoprim & 32 & 64 & $8 \cdot 0-1024$ \\
Sulfamethoxazole & 256 & $>1024$ & $64->1024$ \\
\end{tabular}


$\mathrm{D}$-galactose, gentiobiose, $\alpha$-D-lactose, maltose, $\mathrm{D}$-mannose, D-melibiose, D-raffinose, L-rhamnose, sucrose, D-trehalose, turanose, D-xylose, D-galacturonic acid, D-gluconic acid, D-glucuronic acid, itaconic acid, glucuronamide, Lphenylalanine, D-serine, inosine, uridine, thymidine, cytosine or sebacic acid. The predominant cellular fatty acids are $\mathrm{C}_{18: 1} \omega 7 c, \mathrm{C}_{16: 0}, \mathrm{C}_{12: 0}, \mathrm{C}_{12: 0} 3-\mathrm{OH}$ and $\mathrm{C}_{10: 0} 3-$ $\mathrm{OH}$. Susceptible to aminoglycosides, fluoroquinolones and polymyxin B, but resistant to piperacillin, erythromycin, tetracycline, chloramphenicol, trimethoprim and sulfamethoxazole. The DNA G $+\mathrm{C}$ content of the type strain is $67 \cdot 9 \mathrm{~mol} \%$.

The type strain, MCC $10330^{\mathrm{T}}$ ( = ATCC BAA $-1130^{\mathrm{T}}=\mathrm{DSM}$ $17224^{\mathrm{T}}$ ), and other strains were isolated from the ears of patients with acute otitis externa, acute otitis media with otorrhoea and chronic suppurative otitis media.

\section{References}

Achouak, W., Sutra, L., Heulin, T., Meyer, J. M., Fromin, N., Degraeve, S., Christen, R. \& Gardan, L. (2000). Pseudomonas brassicacearum sp. nov. and Pseudomonas thivervalensis sp. nov., two root-associated bacteria isolated from Brassica napus and Arabidopsis thaliana. Int J Syst Evol Microbiol 50, 9-18.

Anzai, Y., Kim, H., Park, J., Wakabayashi, H. \& Oyaizu, H. (2000). Phylogenetic affiliation of the pseudomonads based on 16S rRNA sequence. Int J Syst Evol Microbiol 50, 1563-1589.

Cashion, P., Holder-Franklin, M. A., McCully, J. \& Franklin, M. (1977). A rapid method for the base ratio determination of bacterial DNA. Anal Biochem 81, 461-466.

De Ley, J., Cattoir, H. \& Reynaerts, A. (1970). The quantitative measurement of DNA hybridization from renaturation rates. Eur J Biochem 12, 133-142.
Huß, V. A. R., Festl, H. \& Schleifer, K. H. (1983). Studies on the spectrophotometric determination of DNA hybridization from renaturation rates. Syst Appl Microbiol 4, 184-192.

Ivanova, E., Gorshkova, N., Sawabe, T. \& 8 other authors (2002). Pseudomonas extremorientalis sp. nov., isolated from a drinking water reservoir. Int J Syst Evol Microbiol 52, 2113-2120.

Kersters, K., Ludwig, W., Vancanneyt, M., De Vos, P., Gillis, M. \& Schleifer, K. H. (1996). Recent changes in the classification of the pseudomonads: an overview. Syst Appl Microbiol 19, 465-477.

Migula, W. (1894). Ube rein neues System der Bakterien. Arb Bakteriol Inst Karlsruhe 1, 235-238 (in German).

Munsch, P., Alatossava, T., Marttinen, N., Meyer, J., Christen, R. \& Gardan, L. (2002). Pseudomonas costantinii sp. nov., another causal agent of brown blotch disease, isolated from cultivated mushroom sporophores in Finland. Int J Syst Evol Microbiol 52, 1973-1983.

NCCLS (2003). Methods for dilution antimicrobial susceptibility tests for bacteria that grow aerobically, 6th edn. Approved Standard M7-A6. Wayne, PA: National Committee for Clinical Laboratory Standards.

Oyauzu, H. \& Komagata, K. (1983). Grouping of Pseudomonas species on the basis of cellular fatty acid composition and the quinone system with special reference to 3-hydroxy fatty acids. J Gen Appl Microbiol 29, 17-40.

Palleroni, N. J. (1984). Genus I. Pseudomonas Migula 1894. In Bergey's Manual of Systematic Bacteriology, vol. 1, pp. 141-199. Edited by N. R. Krieg \& J. G. Holt. Baltimore: Williams \& Wilkins.

Palleroni, N. J., Kunisawa, R., Contopoulou, R. \& Doudoroff, M. (1973). Nucleic acid homologies in the genus Pseudomonas. Int J Syst Bacteriol 23, 333-339.

Roland, P. \& Stroman, D. (2002). Microbiology of acute otitis externa. Laryngoscope 112, 1166-1177.

Sikorski, J., Stackebrandt, E. \& Wackernagel, W. (2001). Pseudomonas kilonensis sp. nov., a bacterium isolated from agricultural soil. Int J Syst Evol Microbiol 51, 1549-1555.

Wayne, L. G., Brenner, D. J., Colwell, R. R. \& 9 other authors (1987). Report of the ad hoc committee on reconciliation of approaches to bacterial systematics. Int J Syst Bacteriol 37, 463-464. 